\title{
The experiences of adults with learning disabilities attending a sexuality and relationship group: "I want to get married and have kids"
}

\author{
Matthew Box, ${ }^{1}$ Jill Shawe ${ }^{2}$
}

${ }^{1}$ Specialist Practitioner Community Learning Disabilities Nursing, Department of Learning Disabilities, Surrey and Borders Partnership NHS Foundation Trust, Kingsfield Centre, Redhill, UK

${ }^{2}$ Senior Research Associate, University College London Institute for Women's Health, London, UK

\section{Correspondence to}

Mr Matthew Box, Department of Learning Disabilities, Surrey and Borders Partnership NHS Foundation Trust, CTPLD East, Kingsfield Centre, Philanthropic Road, Redhill RH1 4DP, UK matthew.box@sabp.nhs.uk

Received 10 October 2012 Revised 10 April 2013 Accepted 23 April 2013 Published Online First 20 June 2013
To cite: Box M, Shawe J. I Fam Plann Reprod Health Care 2014;40:82-88.

\begin{abstract}
Background People with learning disabilities are frequently denied or restricted in their right to express their sexuality by restrictive policies, negative attitudes or lack of awareness of their needs. They also tend to have differing and unrecognised sexual health needs to those of the general population. Evidence suggests that acquiring a greater knowledge and awareness of sexuality and relationship issues helps to decrease these disadvantages and to promote a greater sense of well-being for this group.
\end{abstract}

Methods The experiences of eight adults with learning disabilities attending a sexuality and relationship group, based on a mixture of validated and established sexuality and relationship programmes, were explored using a case study approach. Participants' experiences were gathered through semi-structured interviews and analysed using qualitative content analysis supported by participant observation and pre- and post-group assessment of knowledge.

Results Participant experiences were unique and individual, with few shared opinions. All participants demonstrated increases in their total knowledge scores in the post-group assessment and felt that attending the group had changed their views on relationships; they felt that they were more able to talk to others, to trust someone, to feel confident to want longer relationships and to be married with children. Conclusions Sexuality and relationship groups can offer participants a beneficial and positive experience to explore such issues. The experiences of participants could be enhanced through adopting a person-centred approach and through recognising that participants have individual experiences that may not be shared within the group environment.

\section{INTRODUCTION}

Historically people with learning disabilities have been denied and restricted in

\section{KEY MESSAGE POINTS}

- Sexuality and relationship groups can offer people with learning disabilities a beneficial and positive experience to explore sexuality and relationship issues.

- The experiences of participants attending such a group were unique and individual.

- A person-centred approach needs to be adopted to improve participants' experiences of attending such groups.

the right to express their sexuality, ${ }^{1}{ }^{2}$ including the desire for same sex relationships. ${ }^{3}$ Although attitudes are changing, they still experience difficulties in expressing their sexuality ${ }^{4-6}$ and in developing meaningful relationships. ${ }^{1}$ They also tend to have differing and unrecognised sexual health needs to those of the general population. ${ }^{78}$ They require more support, including sexual health promotion, for their needs to be met. ${ }^{9}$

The term 'learning disability' in this article relates to a significant impairment of intelligence (IQ score below 70) and social function, which commenced before adulthood and which is life-long. ${ }^{10}$ The degree of learning disability can be further subdivided into mild, moderate, severe and profound. ${ }^{10}$ People with learning disabilities may also have other co-morbid diagnoses (e.g. Down's syndrome, autism, physical disabilities, neurological and mental health disorders), which are not always formally diagnosed.

As a result of past and present attitudes, people with learning disabilities are often reluctant to develop their 
sexual lives. ${ }^{4-6}$ Structural and organisational problems restrict relationships from forming and/or developing, ${ }^{1}$ contributing to social isolation ${ }^{11}$ and small social networks. ${ }^{2}$ These individuals have fewer opportunities to engage in consenting sexual relationships ${ }^{12}$ and are less likely to develop positive experiences in their sexual lives. ${ }^{13}$

As a consequence of these attitudes and experiences, many people with learning disabilities feel that they have a lack of privacy in society, ${ }^{14}{ }^{15}$ thinking that they are constantly being monitored and judged. Hingsburger and Tough ${ }^{14}$ describe how a couple think they cannot have sex in their bedroom as "we'd get killed", and instead engage in intimate behaviour in the park as it is seen as somewhat private and safe, and away from staff and others who might punish them.

Many parents are also reticent for people with learning disabilities to engage in sexual relationships. ${ }^{16}$ Despite normally recognising this as their right ${ }^{17}$ they are fearful of their vulnerability. ${ }^{18}$ Indeed numerous parents still support sterilisation as a form of contraception, ${ }^{4}$ especially as they do not trust their child to use reversible contraception and they fear that pregnancy might result from sexual abuse. ${ }^{18}$

This concern is justified, as people with learning disabilities are at high risk of experiencing sexual abuse, ${ }^{19}$ either as victims or as perpetrators. This may be due to their lack of knowledge regarding capacity to consent and the law, ${ }^{20}$ their vulnerability, ${ }^{7}{ }^{21}$ limited sexuality and relationship education ${ }^{13}$ and lack of adequate policies. ${ }^{22}$ There is a higher rate of abuse for women with learning disabilities compared to men, and nearly all the perpetrators are men who themselves have a learning disability. ${ }^{23}$

People with learning disabilities have also been shown to have decreased levels of knowledge and understanding of sexuality and relationship issues ${ }^{24}$ and fewer sexual experiences ${ }^{25}$ compared to the general population. They are less likely to be offered sexual health screening ${ }^{26}$ and are more likely to engage in unsafe sex. ${ }^{27}$

Many parents and carers are fearful that providing sexuality and relationship information for people with learning disabilities will lead to unwanted sexualised behaviours $^{28}$ and will evoke feelings of discomfort. ${ }^{5} 17$ In contrast, many people in society ${ }^{1} 517$ and many health professionals ${ }^{29}$ view people with learning disabilities as asexual and consequently not needing sexual health promotion.

Recognition of the need for, and benefits of, sexuality and relationship education for people with learning disabilities has been demonstrated to support them in developing their needs. ${ }^{9}{ }^{30}$ This is further promoted by reports of group programmes ${ }^{31-33}$ that have been facilitated to help achieve this; these led to increases in knowledge, ${ }^{34}$ decreases in incidences of inappropriate sexualised behaviour, ${ }^{34}$ and positive changes in individuals' attitudes towards their sexuality ${ }^{42}$ and to that of their carers. ${ }^{34}$ People with learning disabilities therefore need to be provided with meaningful sexuality and relationship education that reflects their unique needs. ${ }^{35}$

This study aimed to build upon the evidence base regarding the sexuality and relationship needs of people with learning disabilities, through exploring their experiences of attending a sexuality and relationship group. In particular it aimed to discover what participants liked and did not like about the group, how attendance at the group made participants feel, and how it affected their views and feelings about sex and relationships. The aim was to improve and tailor the facilitation of future groups to meet the needs of participants.

\section{METHODS}

The study used case study methodology ${ }^{36}$ following a qualitative theoretical perspective to explore the experiences of adults with learning disabilities attending a sexuality and relationship group. Data were primarily obtained from semi-structured interviews and supported by participant observation and assessment of pre- and post-group knowledge. Participants for the study were recruited from adults referred to the Community Team for People with Learning Disabilities (CTPLD) requesting sexuality and relationship input. The CTPLD is a National Health Service (NHS) organisation, commissioned to work with any adult with a learning disability requiring specialist health input. Referrals can be made by anyone and can include self-referrals.

Ethical approval was obtained from Surrey Research Ethics Committee and the local NHS Trust.

The researcher approached participants only when it was agreed by professionals within the CTPLD that the individual's needs could be appropriately met through attendance at a sexuality and relationship group. As the study explored a vulnerable group's experience of a sensitive subject, special consideration was given to the ethics of conducting the research and obtaining informed consent from participants. This followed advice from the British Psychological Society's Professional Practice Board ${ }^{37}$ in relation to the Mental Capacity Act, ${ }^{38}$ as well as guidance from a clinical psychologist and speech and language therapist from the CTPLD. A participant information sheet and consent form were devised in an easy-to-read format covering all aspects needed to display informed consent.

Prior to the group starting, participants met with the researcher (who was also the male facilitator of the group) to discuss the topics the group intended to cover and to assess what participants hoped to get out of attending the group. A social and sexual knowledge assessment $^{39}$ was also completed. This is a standardised questionnaire containing 111 questions over 16 
sections. During this visit the researcher discussed what participation in the research study involved, namely observations within the group and a recorded interview of their experiences of the group. It was stressed that if group members did not wish to participate in the study, this would not affect their attendance at the group. Participants were then visited at least 24 hours later to complete the consent form, which was completed in the presence of a person independent of the study (e.g. carer) to ensure that there was no duress or coercion. This allowed participants time to weigh up the information, demonstrate they were able to retain information and decide if they wished to participate.

Participants were informed that the research study would be confidential, but that if they disclosed anything that might indicate a safeguarding concern, this would be reported to the relevant authorities.

The sexuality and relationship group met for ten weekly 2-hour sessions at a local day centre for adults with learning disabilities. The sessions were co-facilitated by a male and a female Learning Disability Community Nurse from the CTPLD, with past experience of running sexuality and relationship groups. Two participants (P2 and P3) were previously known to the researcher, who had completed an assessment of their health needs when they were referred to the CTPLD. None of the participants were previously known to the female facilitator.

Sessions were based on validated and established sexuality and relationship programmes for people with learning disabilities. ${ }^{40-42}$ Topics included: basic anatomy and body differences, puberty, hygiene, menstruation, menopause, sexual activities including same-sex relationships, conception, contraception and safe sex including abstinence, masturbation, wet dreams, self-examination, attractions, different types of relationships, forming and managing relationships, emotions, attitudes including stereotyping, good and bad touch, consent, public and private places, abuse and assertiveness.

Participant observation was undertaken by facilitators to capture group interaction and behaviour, content of language, knowledge and understanding, emotional experiences, and session events.

Following the final session, individual and group social and sexual knowledge assessments ${ }^{39}$ were completed, after which semi-structured interviews were conducted at a subsequent meeting. Both of these typically lasted 1 hour, and took place without carers being present. Interviews followed a topic guide and used open-ended questions, to reduce acquiescence. ${ }^{43}$ Pictures were also used as prompts to address communication difficulties and help participants remember different aspects of the group. ${ }^{43}$ Participants were encouraged to discuss issues and experiences pertinent to themselves. The interviews were recorded and transcribed verbatim and analysed using qualitative content analysis. ${ }^{44}$ This involves the analysis of transcribed speech and takes into account how words are said (e.g. repetition, elaborative speech). Transcripts are analysed by repeatedly reading through them for any themes that emerge and identifying any substantive statements, which are categorised. Emergent themes are then placed on a grid for thematic analysis.

\section{RESULTS}

\section{Group participants}

A profile of the participants who took part in the study is shown in Table 1. The CTPLD is based in an area that is not ethnically diverse and so participants' ethnicity reflects the lack of diversity in the local population. Participant diagnosis was obtained from psychiatric, social and medical records. Although P2 had no formal diagnosis, from the researcher's own experience it was evident that he displayed autistic tendencies. None of the participants in the group were engaged in paid employment and all received benefits as their means of income, which is typical for the vast majority of adults with learning disabilities. ${ }^{11}$

The group consisted of six regular participants (three females and three males), and one female and one male who only attended two sessions each. These two participants were experiencing personal difficulties (e.g. bereavement) when the group ran and therefore requested to attend the next group. One of the regular group participants was unable to demonstrate capacity to give valid consent and was therefore not included in the study.

\section{Social and sexual knowledge assessment}

All study participants demonstrated increases in their total knowledge in the post-group assessments (Table 2).

Table 1 Participants' profiles

\begin{tabular}{llllll}
\hline & Participant & & & & \\
\cline { 2 - 5 } Attribute & P1 & P2 & P3 & P4 & P5 \\
\hline Gender & Male & Male & Male & Female & Female \\
Age (years) & $20-24$ & $45-49$ & $20-24$ & $30-34$ & $25-29$ \\
Ethnicity & White British & White Other & White British & White British & White British \\
Diagnosis & Moderate LD, autism & Mild LD, cerebral palsy & Mild LD, Asperger & Mild LD, epileptic & Moderate LD, paranoid \\
& & & syndrome, ADHD & & schizophrenia, depressive disorder \\
\hline
\end{tabular}

$\overline{A D H D}$, attention deficit hyperactivity disorder; $L D$, learning disability. 
Table 2 Participants' pre- and post-group social and sexual knowledge scores

\begin{tabular}{|c|c|c|c|c|c|c|c|c|c|c|}
\hline \multirow[b]{2}{*}{ Parameter } & \multicolumn{10}{|c|}{ Participant } \\
\hline & $\mathbf{P 1}$ & & P2 & & P3 & & P4 & & P5 & \\
\hline Assessment & Pre & Post & Pre & Post & Pre & Post & Pre & Post & Pre & Post \\
\hline Total score & $55 / 111$ & $70 / 111$ & $80 / 111$ & $98 / 111$ & $92 / 111$ & $99 / 111$ & $93 / 111$ & $98 / 111$ & $49 / 111$ & $63 / 111$ \\
\hline Score change & +15 & & +18 & & +7 & & +5 & & +14 & \\
\hline
\end{tabular}

Participants who had a lower pre-group score achieved a larger number of correct answers in their post-group assessment scores. Participants generally had better knowledge of social aspects of the assessment (social behaviour: kissing and sexual assault; marriage and caring for children), and tended to not score as well in the sexual knowledge sections (masturbation, menstruation and contraception). In particular the only form of contraception most participants were aware of was the condom, despite different forms of contraception being covered in the sessions. The quality of responses to questions also tended to improve in the post-group assessments, with participants giving more detailed answers. As expected, participants with a mild learning disability achieved higher scores than participants with a moderate learning disability.

\section{Sexuality and relationship group assessment}

Participants' individual post-group assessment responses were largely positive and similar to their responses as a group, stating that they liked meeting new people and being around people. Participants tended not to have negative comments except P2 who found the group too noisy and busy.

\section{Semi-structured interviews}

Previous experience of sexuality and relationship education

The participants could not recall having had any significant sexuality and relationship education before attending the group, apart from P3 who remembered having input at school, "They just talked about different [contraceptives] ... like condoms, not much else", and $\mathrm{P} 4$ who had been visited by someone at home.

Experience of participating in the sexuality and relationship group

Participants' general experience of the group was positive, with most participants feeling nervous and scared before they attended their first session, being uncertain about what was going to happen and who would be there, but glad that they attended, feeling happy and safe in the group: "I preferred it in a big group ... It makes me calm and safer - and safe in that room". [P4]

The two female participants initially both wanted their support workers to attend the session with them, but were informed that the group was a private and confidential arena and so non-participants/observers were not allowed, but could sit next door and be available if needed. Both participants appreciated this: "I feel like I'd have liked to have a support worker there anyway just to make sure but, mm, now I've done it on my own and they go next door just to make sure that ... I'm glad I did it anyway". [P4]

Most of the participants felt that the group was about the right size and that the group benefited from being mixed gender. They enjoyed sharing the experience with other group members and some participants formed close relationships, feeling supported by one another. "It's easier to learn things with different kinds of people." [P2] "It was really quite cool having men and women in the group." [P5]

One participant would have preferred an all-male group, suggesting he feels more comfortable in an all-male environment: "Because men are more, [...] I mean they are different, you know, to women". [P1] Participants with milder learning disabilities appeared to benefit from having people with more significant learning disabilities present as they tended to be more open about their feelings and they felt that they could help each other. "I suppose it felt comfortable 'cos erm ... unlike other people, they don't hide if they don't understand everything, they don't pretend." [P2] "It made me feel proud actually ... I felt I could help others ... And it felt good....” [P4]

Participants generally commented favourably about the organisation, venue and time of the group but felt that it was very important to have consistent group facilitation. When one facilitator was replaced for two sessions by another female facilitator the group felt disrupted. "Sometimes if they were different you start all over again ... because people don't know what we have talked about." [P2]

Participants appeared to have preferred the group being facilitated by a male and female together, feeling this added to the overall experience and if they had something personal they wanted to discuss they would talk to a facilitator of the same sex privately: "I have to go to a lady if I wanted someone to talk to someone privately". [P4] This was in relation to discussing sexual attractions she had for someone, which she later discussed within the group as a whole.

\section{Content of programme}

Participants felt that 10 sessions was about the right amount, but the male participants would have liked the sessions to be longer, "as things often became rushed". [P3] The group had agreed on ground rules 
for conduct within the sessions and most participants felt these were beneficial.

Participants in the main talked favourably about session content, and worksheets were thought to be a good to aid communication. They enjoyed the more participatory and energetic activities, such as the attractions exercise where participants discussed why people may fancy one another from pictures they had cut from magazines. "I felt it was great because you get, you know who you like and don't like. That way you learn." [P4] "I think it was fun." [P5]

All participants liked using DVDs, with P1 mentioning the DVD exploring safe sex: "That was helpful because ... for me ... I could just see what that is".

Participants would have liked more role play in the sessions. They talked about how they enjoyed dressing up and feeling they were relaxed, fun and more realistic. Although some participants said they did not enjoy role play, as they felt embarrassed, they appreciated participating, acknowledging that it was good to practise these skills: "the way we learn is to show other people”. [P5]

Participants generally preferred having the sex education sessions before the relationship sessions, as this helped them to better explore the more abstract relationship sessions through having a knowledge base of sexuality topics and terminology used.

Post-group views about sexuality and relationships

All participants felt that the group had positively changed their views on relationships. "I now feel more confident in relationships ... I want [...] to be married with children." [P3] "I can trust someone ... more able to talk to others.” [P5]

Participants appreciated being able to discuss sexuality and relationship issues. "People always talk to me about a lot of things now." [P1] Another felt he now had a better understanding regarding the rules of relationships: "I can work out now about relationships ... work out how they work". [P2]

The majority of participants stated they now felt more confident in relationships, with P3 discussing how he now felt more assertive: "I found it hard to say no to people in the past". He stressed how the 'Rules for Saying No' exercise ${ }^{3}$ allowed him to practise assertiveness techniques that he could transfer outside the group.

Participants in general did not comment upon whether the group made any difference to how they thought about sex and their bodies, although one female participant commented: "I now know my body is changing and that I can talk to someone about sex" [P4], demonstrating an awareness that bodies change through ageing.

\section{Participant observations}

Participant observations generally correlated with the views they had expressed in their semi-structured interviews. Observations indicated that participants benefited from attending the group, showing increased insight into sexuality and relationship issues as the group progressed. This was shown through participants using more appropriate terminology for parts of their body, increasingly responding correctly to questions and activities and, most importantly, gradually feeling more able to discuss sexuality and relationship issues.

Observations also indicated that all but one participant enjoyed the shared experience. Participants showed respect for one another and frequently encouraged and praised each other when they did something well. Participants with milder learning disabilities tended to support and encourage participants with more significant learning disabilities, who often lost concentration during more discussion-based exercises. All participants appeared to benefit from using pictorial aids to support teaching, which allowed them to gain a better understanding of what was being discussed and then to formulate their thoughts.

\section{DISCUSSION}

Participants' experiences of attending a sexuality and relationship group in this case study were unique and individual, with participants often sharing positive experiences of one aspect of the group and not of another. This was highlighted in the semi-structured interviews where participants tended to talk more about subjects important to them, which differed for each participant, and the reasons why they did or did not enjoy a particular aspect of the group also often differed for each participant. Although this may suggest that it is difficult to have fixed rules in the facilitation of a sexuality and relationship group, the findings from the data can assist in improving the facilitation of future groups, through adopting a more person-centred approach. ${ }^{11} 45$ Thought should therefore be given to changing the recruitment procedure for future groups and improving the assessment process. This would include gathering more information of potential participants' wants and needs before the course, including their past experiences of attending groups and their preferred learning styles. However, it is acknowledged that this would be more time consuming and there may not be sufficient numbers of potential participants to make up groups with similar needs.

The data indicate that the general experience of the group was positive, which is reflected in participants' high attendance record. The fact that the two participants who knew the researcher prior to the group did not mention this in their semi-structured interviews would indicate that this had little significance regarding their experience of the group. Participants talked favourably about session content, with the majority saying they enjoyed the sessions that tended to be more practical. The male participants commented that 
they also enjoyed the menstruation and sexual activities session, which was more discussion-based using pictures, as they had not previously explored this. The female participants appeared comfortable discussing this area with the males present.

Participants enjoyed being in a mixed-gender group and learning from each other. For many participants this may have been the first time they had experienced sharing intimate and personal experiences with members of the opposite sex, and as such the group was very revealing and liberating for them. This is in contrast to previous literature ${ }^{42} 46$ that suggests that single-sex groups are preferable to mixed groups.

Participants appeared to have enjoyed and benefited from sharing the experience with other group members, speaking fondly of one another. It has been recognised that people with learning disabilities gain from being in groups through sharing their experiences and listening to the opinions of other group members. ${ }^{7}$ Indeed as the group progressed, participants showed a greater respect for one another and appreciated that people have differing needs and feelings in relation to sexuality and relationships. Although some participants still struggled with this, the fact that they demonstrated a positive change in self-awareness helps to demonstrate the positive nature of attending a group. However, it needs to be recognised that individual work would be more appropriate for some people ${ }^{7}$ for instance, if they feel uncomfortable discussing personal issues due to past experiences of abuse, or if they find the proximity of others distressing due to autism.

Limitations of the study included the small sample size, reducing its ability for its findings to be generalisable. In addition, the participants were all known to the researcher as he co-facilitated the group, which may have inhibited them in discussing negative experiences within the interviews. However, past research studies interviewing people with learning disabilities indicate that participants feel embarrassed discussing sexuality issues with a stranger, and will talk more openly with group facilitators. ${ }^{4}$

\section{CONCLUSIONS}

This study, which explored the experiences of adults with learning disabilities attending a sexuality and relationship group, has shown that participants' experiences are unique and individual. Participants indicated that their experiences were largely positive and beneficial and the future running of similar groups should therefore be encouraged.

Acknowledgements The authors would like to thank the participants who took part in this study, and Susann Stone who co-facilitated the group.

\section{Competing interests None.}

Ethics approval Ethical approval for this study was obtained from Surrey Research Ethics Committee and the local NHS Trust.
Provenance and peer review Not commissioned; externally peer reviewed.

\section{REFERENCES}

1 Lesseliers J. A right to sexuality? Br J Learn Disabil 1999;27: 137-140.

2 Carson I, Docherty D. Friendships, relationships and issues in sexuality. In: Race D (ed.), Learning Disability - A Social Approach. London, UK: Routledge, 2002:139-153.

3 Lofgren-Martenson L. The invisibility of young homosexual women and men with intellectual disabilities. Sex Disabil 2009;27:21-26.

4 Withers P, Ensum I, Howarth D, et al. A psycho educational group for men with intellectual disabilities who have sex with men. J Appl Res Intellect Disabil 2001;14:327-339.

5 Aunos M, Feldman M. Attitudes towards sexuality, sterilization and parenting rights of persons with intellectual disabilities. J Appl Res Intellect Disabil 2002;15:285-296.

6 Thomas G, Kroese B. An investigation of students' with mild learning disabilities reactions to participating in sexuality research. Br J Learn Disabil 2005;33:113-119.

7 Sant Angelo D. Learning disability community nursing: addressing emotional and sexual health needs. In: Astor R, Jeffereys K (eds), Positive Initiatives for People with Learning Difficulties. Basingstoke, UK: MacMillan Press Ltd, 2000:52-68.

8 Peate I, Maloret P. Testicular self-examination: the person with learning disabilities. Br J Nurs 2007;16:931-935.

9 Grieveo A, McLaren S, Lindsay W. An evaluation of research and training resources for the sex education of people with moderate to severe learning disabilities. Br J Learn Disabil 2006;35:30-37.

10 World Health Organization. The ICD-10 Classification of Mental and Behavioural Disorders. Clinical Descriptions and Diagnostic Guidelines. Geneva, Switzerland: World Health Organization, 1992.

11 Department of Health. Valuing People: A New Strategy for Learning Disability for the 21st Century. London, UK: HMSO, 2001.

12 Wheeler P, Jenkins R. The management of challenging sexual behaviour. Learn Disabil Pract 2004;7:28-35.

13 Ailey S, Marks B, Crisp C, et al. Promoting sexuality across the life span for individuals with intellectual and developmental disabilities. Nurs Clin North Am 2003;38:229-252.

14 Hingsburger D, Tough S. Healthy sexuality: attitudes, systems, and policies. Res Pract Persons Severe Disabl 2002;27:8-17.

15 Hollomotz A. 'May we please have sex tonight?' - people with learning difficulties pursuing privacy in residential group settings. Br J Learn Disabil 2008;37:91-97.

16 Evans D, McGuire B, Healy E, et al. Sexuality and personal relationships for people with an intellectual disability. Part II: staff and family carer perspectives. J Intellect Disabil Res 2009;53:913-921.

17 McDonagh R. Too sexed-up! J Adult Prot 2007;9:27-33.

18 Patterson-Keels L, Quint E, Brown D, et al. Family views on sterilization for their mentally retarded children. J Reprod Med 1994;39:701-706.

19 McCormack B, Kavanagh D, Caffrey S, et al. Investigating sexual abuse: findings of a 15-year longitudinal study. J Appl Res Intellect Disabil 2005;18:217-227.

20 O'Callaghan A, Murphy G. Sexual relationships in adults with intellectual disabilities: understanding the law. J Intellect Disabil Res 2007;51:197-206. 
21 Bell D, Cameron L. The assessment of the sexual knowledge of a person with severe learning disability and a severe communication disorder. Br J Learn Disabil 2003;31: 123-129.

22 Fyson R, Kitson D. Independence or protection - does it have to be a choice? Reflections on the abuse of people with learning disabilities in Cornwall. Crit Soc Policy 2007;27:426-436.

23 McCarthy M, Thompson D. A prevalence study of sexual abuse of adults with intellectual disabilities referred for sex education. J Appl Res Intellect Disabil 1997;10:105-124.

24 Galea J, Butler J, Iacono T, et al. The assessment of sexual knowledge in people with intellectual disability. J Intellect Dev Disabil 2004;29:350-365.

25 McCabe M, Cummins R. The sexual knowledge, experience, feelings and needs of people with mild intellectual disability. Educ Train Ment Retard Dev Disabil 1996;3:13-21.

26 Healthcare Commission. Performing Better? A Focus on Sexual Health Services in England. London, UK: Healthcare Commission, 2007.

27 Cambridge P. Men with learning disabilities who have sex with men in public places: mapping the needs of services and users in South East London. J Intellect Disabil Res 1996;40: 241-251.

28 Valenti-Hein D, Dura J. Sexuality and sexual development. In: Jacobson J, Anton J (eds), Manual of Diagnosis and Professional Practice in Mental Retardation. Washington, DC: US American Psychological Association, 1996;301-310.

29 Earle S. Disability, facilitated sex and the role of the nurse. J Adv Nurs 2001;36:433-440.

30 Blanchett W, Wolfe P. A review of sexuality education curricula; meeting the sexuality education needs of individuals with moderate and severe intellectual disabilities. Res Pract Persons Severe Disabil 2002;27:43-57.

31 Sheppard L. Growing pains: a personal development program for students with intellectual and developmental disabilities in a specialist school. J Intellect Disabil 2006;10:121-142.

32 Sant Angelo D. Group think. Can group work with people with learning disabilities be an effective approach? Learn Disabil Res Pract 2001;3:26-28.
33 McGaw S, Ball K, Clark A. The effect of group intervention on the relationships of parents with intellectual disabilities. J Appl Res Intellect Disabil 2002;15:354-366.

34 Plunkett P. An evaluation of a community-based sexuality education program for individuals with developmental disabilities. Electron J Hum Sex 2002;5. http://www.ejhs.org/ volume 5/plunkett/references.html [accessed 5 October 2012].

35 Peate I. Men's Sexual Health. London, UK: Whurr Publishers Ltd, 2003.

36 Yin R. Case Study Research. Design and Methods (4th edn). Thousand Oaks, CA: Sage Publications, 2009.

37 British Psychological Society, Professional Practice Board. Conducting Research With People Not Having the Capacity to Consent to Their Participation. A Practical Guide for Researchers. Leicester, UK: British Psychological Society, 2008.

38 HMSO. Mental Capacity Act. London, UK: Crown Copyright, 2005.

39 Fraser J. Not a Child Anymore. Birmingham, UK: Brook Publications, 1987.

40 McCarthy M, Thompson D. Sex and the 3Rs. Rights, Responsibilities and Risks. A Sex Education Package for Working with People with Learning Difficulties (Revised Edition). Brighton, UK: Pavilion, 1998.

41 Craft A. Living Your Life: The Sex Education and Personal Development Resource for Special Education Needs. London, UK: Brook Publications, 2003.

42 Kerr-Edwards L, Scott L. Talking Together ... About Sex and Relationships. A Practical Resource for Schools and Parents Working with Young People with Learning Disabilities. London, UK: Family Planning Association, 2003.

43 Sigelman C, Budd E, Spanhel C, et al. When in doubt, say yes: acquiescence in interviews with mentally retarded persons. Ment Retard 1981;19:53-58.

44 Gillham B. Research Interviewing: The Range of Techniques. Maidenhead, UK: Open University Press, 2005.

45 Department of Health. Valuing People Now: A New Three-Year Strategy for Learning Disabilities London, UK: Department of Health Publications, 2009.

46 McCarthy M. Sexuality and Women with Learning Disabilities London, UK: Jessica Kingsley Publishers, 1999. 